\title{
Fent recerques amb grills (o cucs de la farina, o formigues...) al laboratori
}

\author{
Xavier Espadaler \\ Unitat d'Ecologia, Dept. de Biologia Animal, de Biologia Vegetal i d'Ecologia (U. Autònoma de Barcelona) \\ Joan Aliberas \\ IES Josep Puig i Cadafalch, Mataró
}

Mantenir un terrari amb grills -o altres insectes- vius pot permetre la realització d'atractius treballs de recerca amb aquests petits insectes. La seva cura no és difícil, però imposa algunes exigències que cal respectar.

Mantenir vius i fer criar grills al laboratori o a l'aula no és una tasca difícil, però permet realitzar recerques més o menys complexes, tant a Primària com a ESO i Batxillerat.

\section{Criar grills domèstics,} Acheta domesticus (L.), al laboratori?

Necessitareu grills adults o quasi adults (aguanten més que els juvenils). Es poden trobar en botigues d'animals (serveixen d'aliment per als rèptils). Preu orientatiu: una dotzena d'adults, uns 2 euros.

Caldrà comprar o preparar un terrari de vidre (mínim $30 \times 20 \times 20 \mathrm{~cm}$ ). Es pot construir amb peces de vidre unides amb silicona (fig. 1).

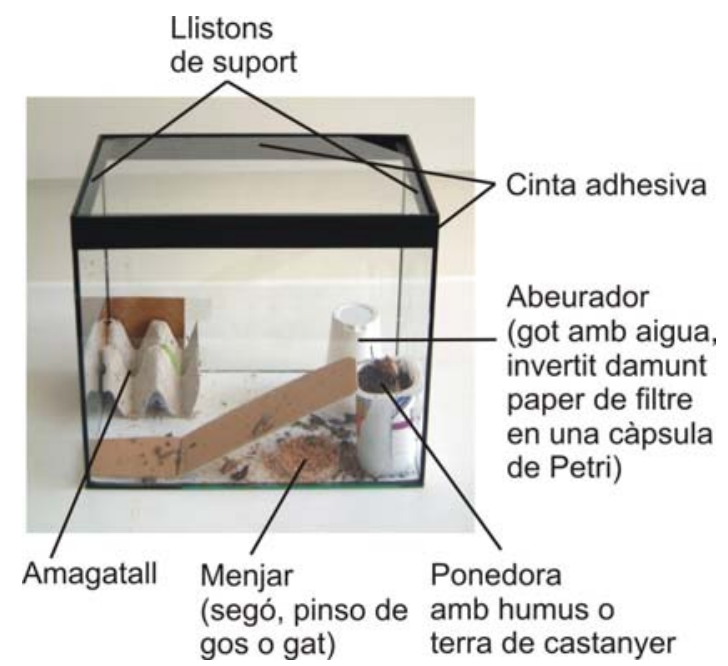

Figura 1. Disposició dels elements del terrari.
Compte! No es podrà usar com a aquari, ja que no aguantaria la pressió.

És recomanable subjectar la seva part superior amb cinta adhesiva.

Com a tapadora pot servir un vidre escapçat d'una punta, per poder-lo agafar amb facilitat, que descansa en dos petits llistons enganxats a les parets, o en perfils en $L$ (per exemple de 0,5 $1 \mathrm{~cm}$ ), que es poden trobar en ferreteries.

Dins del terrari hi haurà d'haver un amagatall on els grills puguin estar relativament a les fosques, que es pot fer amb cartró d'ouera. També necessiten la humitat que proporciona un abeurador fet amb una càpsula de Petri, paper de filtre (o cotó fluix) i un vas de plàstic (fig. 2).

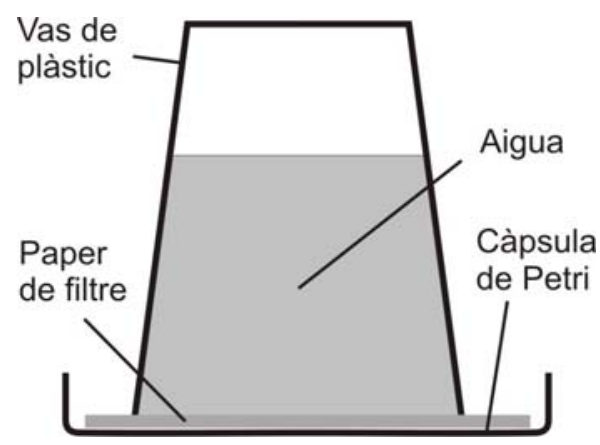

Figura 2. Diagrama de l'abeurador.

Caldrà tenir cura de vigilar el nivell de l'aigua i la provisió d'aliment: tant pot fer-se servir segó (en venen per ajudar a regular el trànsit intestinal) com menjar per a gats, del que ja venen preparat. Tam- 
bé se'ls pot donar de tant en tant una fulla d'enciam.

Una senzilla ponedora per als ous (fig. 3) es pot fer amb un vas de iogurt omplert d'humus o terra de castanyer. Caldrà posar una rampa perquè els grills hi puguin accedir.

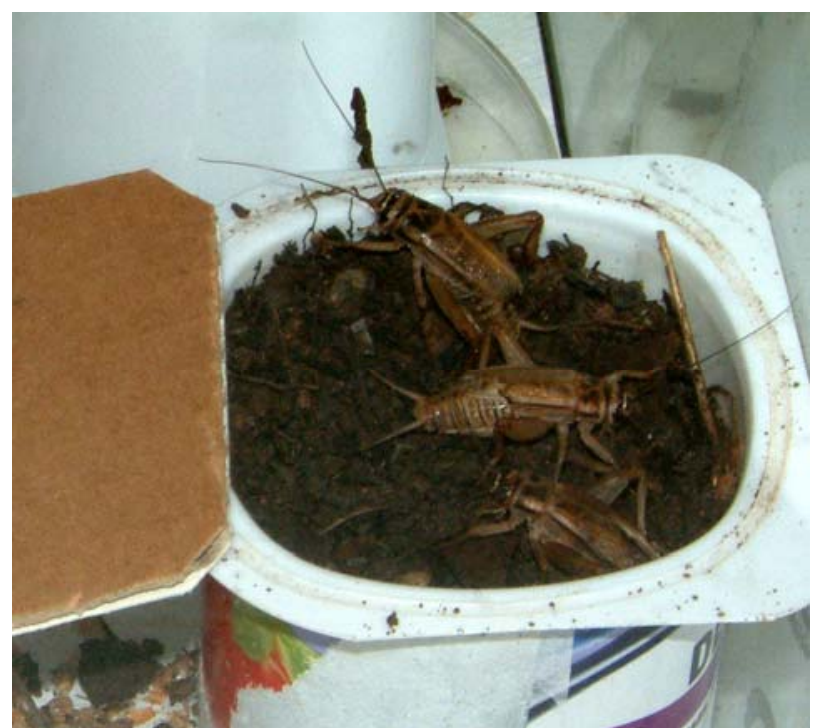

Figura 3. Tres femelles ponent a la terra. Amb el seu llarg ovipositor hi dipositen els ous a una fondària d'entre 5 i $10 \mathrm{~mm}$.

Per facilitar la neteja va bé cobrir tot el fons amb un full de paper de filtre.

Si penseu estudiar-ne el cant, haureu de disposar d'una gravadora digital i de programes de lliure accés (vegeu Bibliografia).

Un cop ja és tot en funcionament, podem passar a fer les recerques.

\section{Fer recerques amb grills?}

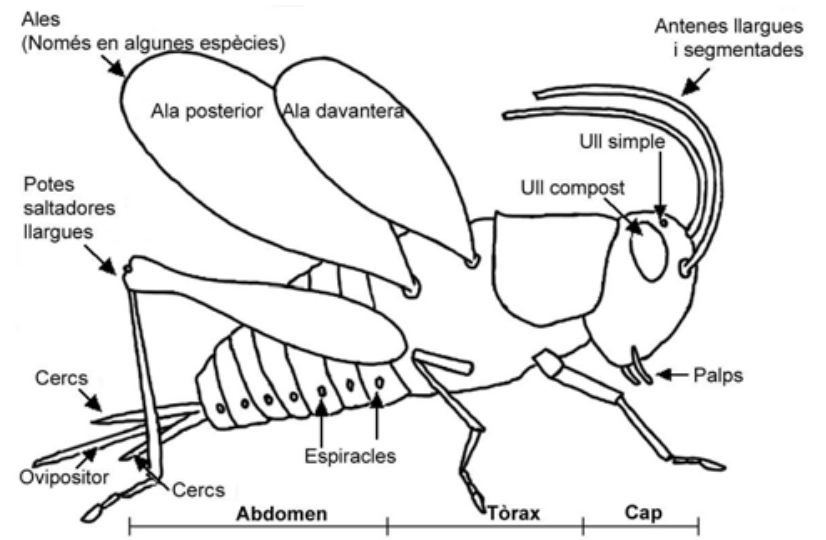

Figura 4. Anatomia externa del grill. (Font: www.enchantedlearning.com)
A Primària i a l'ESO es poden utilitzar per fer recerques senzilles:

- Aprendre a localitzar i nomenar les parts del seu cos (fig. 4).

- Distingir els mascles de les femelles segons la seva diferent morfologia (fig. 5).

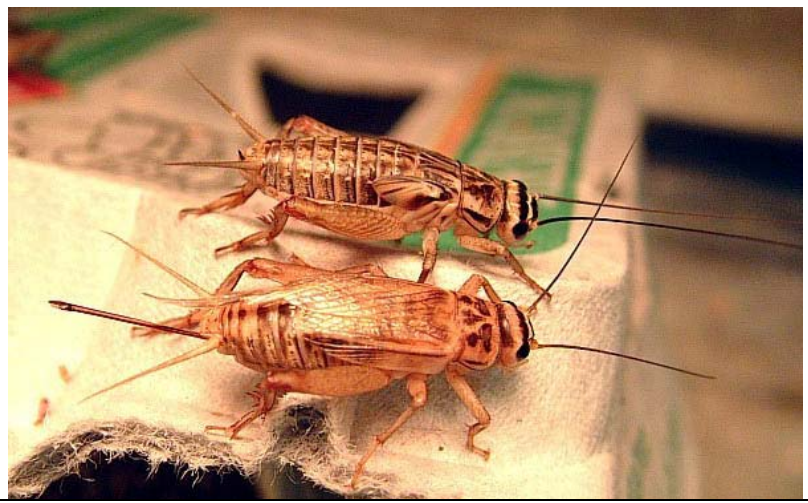

Figura 5. Mascle (a dalt) i femella (a baix) del grill domèstic (Acheta domesticus). La diferència morfològica més destacada entre els dos sexes és el llarg conducte que les femelles tenen al darrera, l'ovipositor. (Font: Department of Entomology, University of Nebraska)

- Tenir mascles i femelles en grups separats. Al posar una femella amb les mascles es produirà un bonic concert.

- Es pot observar el comportament dels grills, les seves preferències pel que fa a la llum o a la humitat; com s'alimenten; com és la seva metamorfosi (anomenada incompleta o gradual: els individus fan la muda però mantenen la forma, augmentant de mida; també la tenen els saltamartins i el tèrmits).

- Com canten (els mascles o les femelles?) en el festeig; com competeixen (per un mascle o per una femella?), com s'aparellen; com ponen els ous, com neixen les cries.

- Com va canviant el seu comportament a mida que es fan grans.

- Què fan amb els que han mort (segons que tinguin o no problemes d'alimentació la conducta pot variar), etc.

Pel que fa al batxillerat es podrien fer recerques més elaborades, com per exemple:

- Investigar quines diferències hi ha entre els dos tipus de cant dels mascles, analitzant-ne l'espectre de freqüències. Canvia la postura dels mascles en els dos tipus de cant?

- Establir si hi ha relació entre la freqüència del cant i la temperatura ambient. 
- Posar un mascle petit i un de gran davant d'una femella i deixar-los festejar. Enregistrar els cants i veure a quin tria la femella. Intentar interpretar la tria en relació amb el cant.

- Quan acaben de mudar són blancs, però de vegades les mudes no són gaire evidents. Se'n pot fer un seguiment aïllant alguns individus $i$ anant-los mesurant la llargada del cos o l'amplada del cap sota la lupa. (Per poder fer-ho amb comoditat es poden posar una estona sobre els dipòsits de fred de les neveres portàtils, fins que queden mig anestesiats). Al fer-ne la gràfica al llarg del temps es veuran uns augments sobtats que cal interpretar com a mudes.

- Quantes vegades muda cada individu? També es pot investigar si el nombre i el ritme de les mudes depenen de la temperatura 0 de l'aliment.

- Encara que les clofolles produïdes en la muda solen menjar-se-les, si se'n pot observar alguna amb la lupa binocular, es pot contemplar la bonica imatge de les tràquees subdividint-se.

- És interessant fer un cultiu dels seus excrements. D'aquesta manera es poden observar els microorganismes del seu tub digestiu. Si els excrements es posen en aigua, al cap d'una setmana a temperatura ambient (o al cap de dos dies si es deixen al sol) s'hi podran observar ciliats amb el microscopi.

- Es pot quantificar la producció d'excrements d'un sol individu; per exemple, pesant els que genera en vuit hores.

- Demostrar si hi veuen. Es pot construir una superfície cilíndrica amb folis o cartolines, amb un diàmetre aproximat de $40 \mathrm{~cm}$, posant-hi algunes tires estretes de color negre (fig. 6). Al deixar el grill al mig, anotar en quina direcció ha anat. Estadísticament serà possible decidir si trien preferentment les bandes fosques i, argumentant amb la possibilitat d'altres sentits (olfacte?), si hi veuen o no.

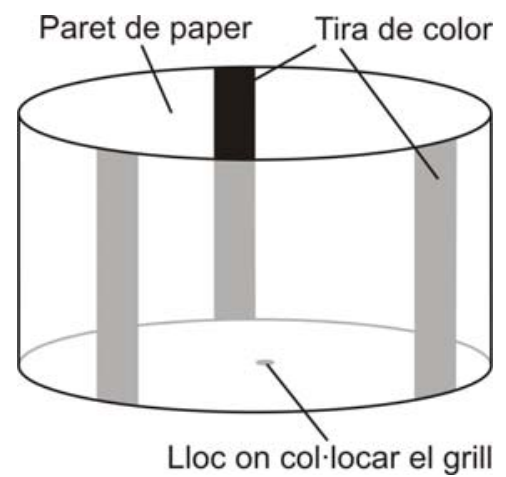

Figura 6. Dispositiu per estudiar si els grills hi veuen.
- De manera semblant, es pot determinar si distingeixen colors, encara que no tinguin un sistema visual com el nostre. Es tractaria de repetir el muntatge anterior però substituint les tires negres per altres de diversos colors.

- Es poden fer estudis d'embriologia amb els ous. Es pot fer un seguiment de com evolucionen, des de la posa fins que s'obren, cosa que a una temperatura de $20^{\circ} \mathrm{C}$ suposa uns 15 dies. Al llarg d'aquest temps, si es volen observar, s'hauran de col-locar sobre un paper humit. Una alternativa és anar a busca una mostra al ponedor cada dia (sempre que no hi hagi post ningú més).

\section{Criar cucs de la farina (Tenebrio molitor L.)}

Aquest és un escarabat (ordre Coleoptera) fàcil de criar i que pot il.lustrar molt bé les quatres "vides" que té un insecte amb metamorfosi completa (força diferent, doncs, de la dels grills):

\section{Ou $\rightarrow$ Larva $\rightarrow$ Pupa o nimfa $\rightarrow$ Adult (fig. 7)}

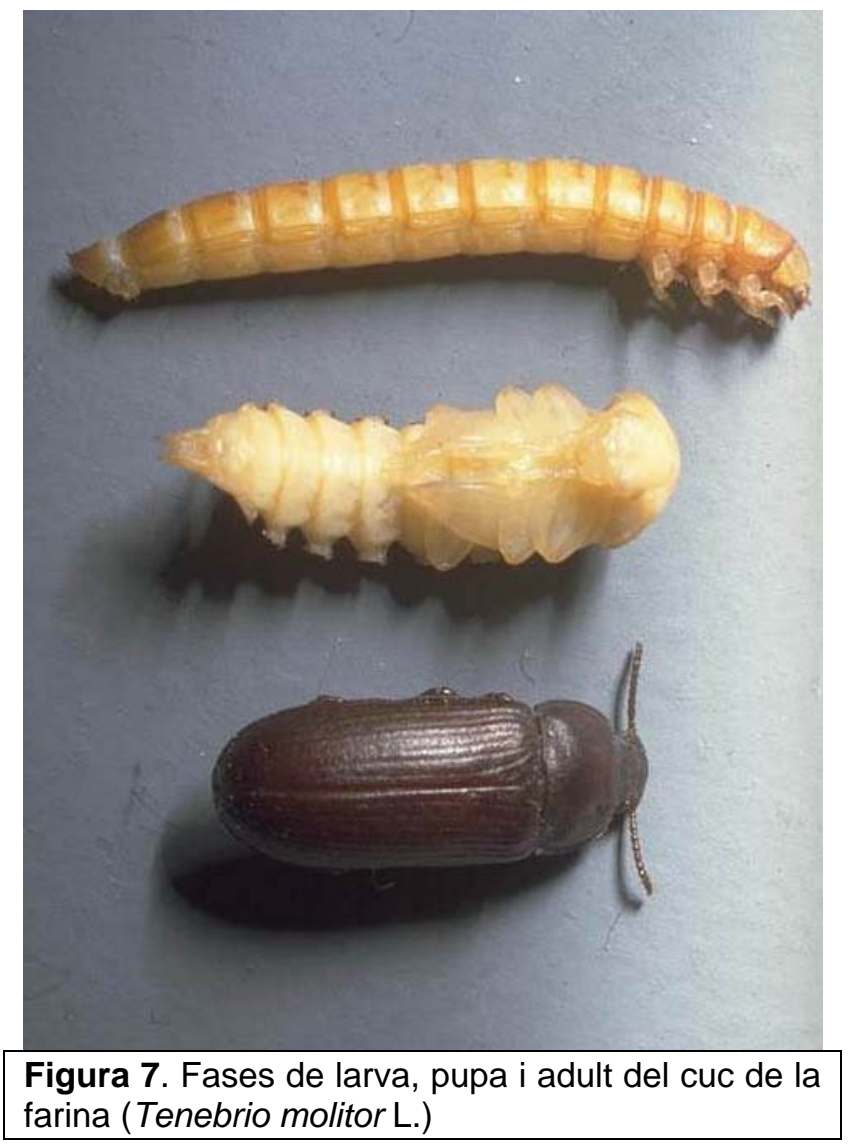

També es poden trobar en establiments de fauna (igualment que els grills, serveixen com a ali- 
ment per a rèptils). Preu orientatiu: un centenar de larves, 3 euros.

Es tracta d'una espècie capaç de viure en un ambient tan eixut com és la farina. Si ho pot fer és perquè pot generar aigua metabòlicament a partir de l'aliment (hidrats de carboni).

Per criar-los caldrà un recipient (la forma és indiferent), amb la boca prou ampla per poder manipular els animals. Es pot construir un terrari semblant al dels grills, però un pot de vidre de boca ampla també pot servir; un túper, també.

Aliment: abundant segó i, de tant en tant (dos cops al mes), una mica d'enciam o un tall de poma com a font d'humitat.

Al recipient hi apareixeran pupes, immòbils, però que tenen un únic tipus de moviment (a descobrir...!) que també té una utilitat (a proposar...!). Triguen dues o tres setmanes per sortir com a adults; quan ho fan són de color groc i al cap d'un parell de dies es tornen més foscos a causa de la melanina.

Segons la temperatura del laboratori, la nimfosi (fase de nimfa) dura més o menys (2 o 3 setmanes). Llavors apareixen els adults, difícils de sexar. Si s'isolen en un recipient de 5 a 10 adults, s'observen còpules fàcilment. El festeig no és gens elaborat ni aparent. Els adults fan una olor ben característica, una mica acre (deguda al despreniment de quinones i fenols).

La metamorfosi incompleta dels grills suposa un desavantatge evolutiu respecte de la completa dels cucs de la farina. Mentre que grills que estan en diferents fases de creixement s'alimenten del mateix i, per tant, competeixen entre ells, els cucs de la farina tenen una alimentació diferent en cadascuna de les seves fases de metamorfisme. Així, en la fase d'ou s'alimenten de les substàncies nutritives que conté; en la fase de larva mengen una mica de tot el que trobin però en especial de qualsevol tipus de matèria farinàcia; en la de pupa no mengen i en la d'adult mengen poc però bàsicament matèries farinàcies. L'avantatge el demostra també el gran nombre d'espècies d'insectes amb metamorfosi completa que coneixem: unes set vegades més gran que els que la tenen incompleta.

Aquestes són algunes de les recerques que es poden fer amb cucs de la farina:

- Explorar la relació entre temperatura i duració de la fase larvària, de la fase de pupa o de la vida com adult establint, per exemple, tres cultius a diferents temperatures $\left(20^{\circ} \mathrm{C}, 25^{\circ} \mathrm{C}, 30^{\circ} \mathrm{C}\right)$. És lineal la relació? (Vegeu a la bibliografia les dades força diferents que proposen els autors!) Poden correspondre a soques diferents? Hi ha hagut algun procés de selecció artificial, evolutivament molt ràpid?

- Les larves senten atracció per la llum o en fugen? Per a investigar-ho prepareu unes coordenades polars (fig. 8) i un flexo de taula amb una bombeta de $100 \mathrm{~W}$ posat de manera que faci incidir la llum aproximadament a $45^{\circ}$ respecte dels sectors 36-1. Poseu una larva al centre, mirant cap amunt. En encendre el llum veureu què fa la larva: per quin sector surt? Repetiu-ho amb altres larves fins a obtenir un centenar de respostes.

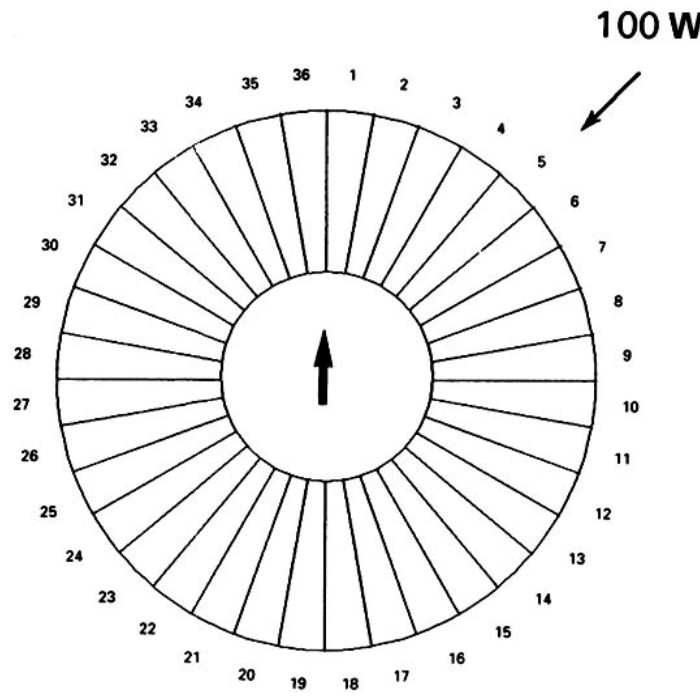

Figura 8. Coordenades polars amb 36 sectors de $10^{\circ}$ cadascun i numerats.

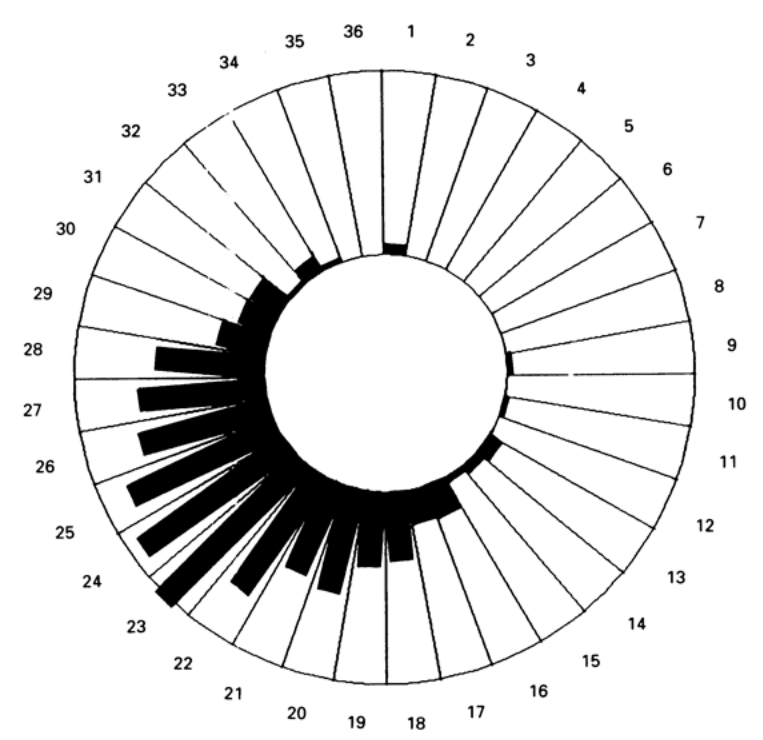

Figura 9. Representació d'unes 150 respostes de larves de Tenebrio amb llum incident de la dreta uns $45^{\circ}$.

- Fugen de la llum o de la calor? Busqueu la manera de separar els dos tipus d'estímul que proporciona el flexo.

- Investigueu la utilitat dels moviments abdominals que mostren les pupes. Poseu-les damunt 
d'una superfície amb farina, o amb segó, o amb fullaraca, i mesureu el temps que triguen en desaparèixer dins dels diferents substrats. Fer l'experiència a plena llum o en foscor (o amb llum vermella). Són iguals els resultats?

- Com poden detectar la llum les pupes? Estudieu-les sota la lupa binocular i proveu d'identificar-hi futurs ulls, futures potes i futures ales.

\section{Criar formigues}

Hi ha molts tipus de formiguer artificial, però cal tenir en compte que el millor material és el més senzill. És mot difícil fer formiguers amb vidre, perquè al no haver-hi ventilació hi apareixen fongs i tot el sistema es degrada. La utilització de terra pot portar molts problemes d'infeccions i fer inviable el formiguer.

Una bona manera de decidir quin podem usar és visitar www.lamarabunta.org i a l'apartat "Cría de hormigas" triar entre una munió d'experiències, tipus de nius i solucions de problemes de manteniment, d'humitat, d'alimentació, etc. (Encara que afirmen que és fàcil, de fet no ho és). Es tracta d'una web molt recomanable, ja que tota mena d'aficionats a la cria de formigues hi intercanvien generosament els seus coneixements i experiència i els posen a disposició dels que s'hi vulguin iniciar. s'hi pot trobar molta informació per construir un bon formiguer i per criar-hi les formigues. També hi proposen recerques per fer amb lles formigues.

Per fer les observacions caldrà una bona lupa (tipus "Sherlock Holmes") o, millor, una lupa binocular que farà l'observació menys cansada.

El problema més important a solucionar és trobar les formigues. La situació ideal és poder comptar amb una societat sencera: reina, covada (ous, larves, pupes) i obreres.

La solució rau en poder capturar, amb un aspirador entomològic (fig. 10), el màxim nombre d'elements de la colònia quan aixequem una pedra i veiem que hi ha molt de personal. És cosa d'anar ràpid! No és senzill però tampoc impossible: es tracta d'insistir.

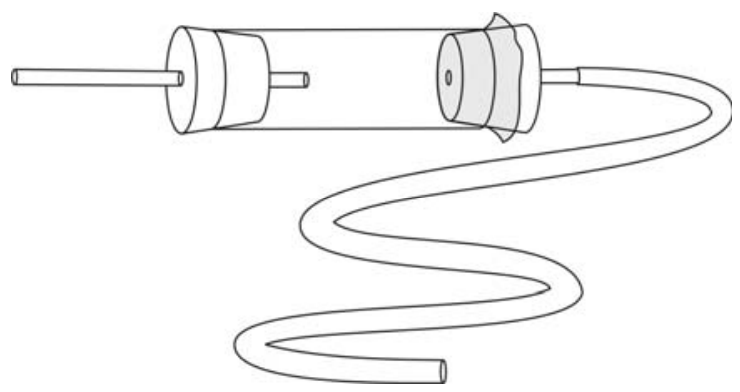

Figura 10. Aspirador entomològic. L'extrem del tub de goma serveix per aspirar un cop s'ha acostat l'altre extrem a la formiga que es vol capturar.
Un cop en funcionament es poden realitzar algunes recerques sobre la vida de les formigues: Dins l'apartat del fòrum La Marabunta, "Mirmecologia general", aneu al subfòrum "Experimentos".

\section{Bibliografia}

\section{Sobre cria i manteniment d'insectes (entre altres petits animals):}

Dournaud, J. \& Dournaud, J. 1993. Cría de pequeños animales. Ed. Octaedro.

\section{Sobre grills:}

Així canten els grills domèstics: http://creatures.ifas.ufl.edu/misc/crickets/domest.wa $\underline{v}$

Software d'anàlisi de so: http://www.telebyte.com/pioneer/ (la versió de lliure accés dura 30 dies)

http://www.visualizationsoftware.com/gram.html (la versió de lliure accés dura 10 dies)

http://www.birds.cornell.edu/brp/Canarylnfo.html (programa de lliure accés per Mac)

\section{Sobre Tenebrio:}

http://www.naturamuseo.org/tienda/ficha7.htm http://www.unne.edu.ar/cyt/biologia/b-011.pdf http://www.xtec.es/cdec/portada/pdf/tenebrio.pdf

\section{Sobre formigues:}

www.lamarabunta.org 